------مجلة علوم الرافدين، المجلد 27، العدد 4 عدد خاص بالمؤتمر العلمي الثالث لعلوم الحياة ، ص 212-222، 2018------

$$
\text { مقارنة بعض صفات مياه الزاب الاسفل مع تجمع لمياه جوفية قريبة منه }
$$

E-mail: Bluesky198379@gmail.com E-mail:mr.mismail76@gmail.comＥ-mail:Abomaith@yahoo.com

$$
\text { (أستلم 2018/9/16 ) (2018/11/ }
$$

$$
\begin{aligned}
& \text { الملخص } \\
& \text { تتاولت الدراسـة الحالية مقارنـة بين نوعيـة ميـاه نهر الزاب الأسفل مـع تجمـع لميـاه العين القريبة منـه في ناحيـة الزاب }
\end{aligned}
$$

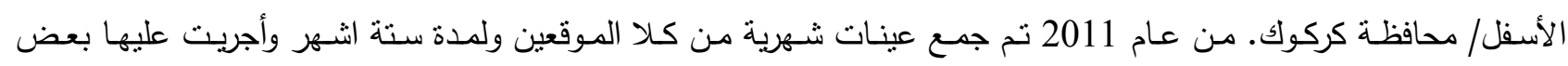

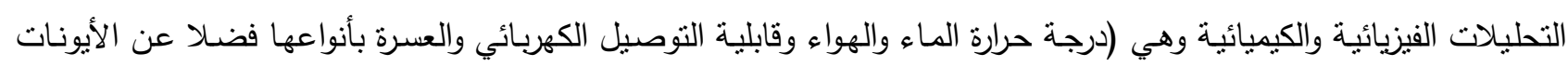

$$
\begin{aligned}
& \text { السالبة والموجبة) أما من الجانب البيولوجي فقد نم حساب العدد الكلي للبكتيريا. } \\
& \text { بينت نتائج الدراسة الحالية حصول تغيرات واضحة في قيم هذه المتغيرات في بعض أنثهر السنة، إذ تراوحت قيم العسرة }
\end{aligned}
$$

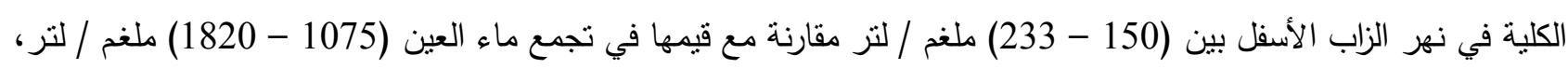

$$
\begin{aligned}
& \text { في حين اظهر تركيز أيون الكلوريد ارتفاعا واضحا في تجمع ماء العين بلغ (2749) ملغم /لتر خلال شهر ايلول مقارنـة مع مياه }
\end{aligned}
$$

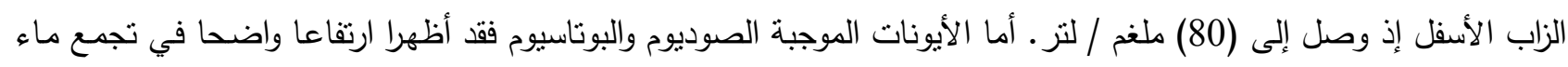

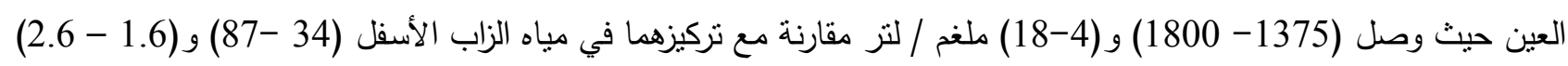

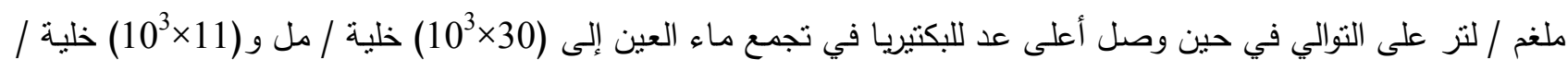

$$
\begin{aligned}
& \text { مل في ماء الزاب الأسفل. }
\end{aligned}
$$

الكلمات الدالة: الزاب الاسفل، العين، كيمائية.

\title{
Comparison Between some Water Characters of the Lesser Zap with an Impoundment Ground Water Close to it
}

\author{
Abdulmoneim M. Ali Kannah Mahmood I. Al-Jubouri Ayesha W. Aumary \\ Department of Biology/College of Science / University of Mosul
}

\begin{abstract}
The current study is a comparative between the quality of water in the river lesser Zap with an impoundment ground water close to it, The two sampling areas are located in the Kirkuk city. In 2011, monthly samples were collected from both sites for a period of six months. Some physical and chemical analyzes were conducted (water and temperature, electrical conductivity and hardness). As well as positive and negative ions). On the biological side, the total number of bacteria was numerated.

The results of the present study showed clear variations in the values of these variables in some months of the year. The total hardness values in lesser Zab ranged between $(150-233) \mathrm{mg} / 1$ compared with their values in an impoundment ground water $(1075-1820) \mathrm{mg} / \mathrm{l}$. The chloride ion concentration showed clear rise in an impoundment ground water $2749 \mathrm{mg} / 1$ during September month compared with water tributary Zab reaching $80 \mathrm{mg} / \mathrm{l}$. The positive ions, sodium and
\end{abstract}


potassium, showed a clear increase in an impoundment ground water (1375-1800) and (4-18) $\mathrm{mg} /$ 1 compared with their concentration in the water lesser Zab (34-87) and (1.6- 2.6) $\mathrm{mg} / 1$ respectively, while the highest count of bacteria in an impoundment ground water were $(30 \times 103)$ cells $/ \mathrm{ml}(11 \times 103)$ cells $/ \mathrm{ml}$ in lesser Zab.

Keywords: Lesser Zap, ground water, chemical.

\section{المقدمة}

من المعروف أن الموارد المائية المتاحـة للاستخدام في تتـاقص مستمر نتيجـة للزيادة السكانية وزيـادة معدلات الطلب المتزايد للحياة، لذلك أصبح إلزاما النتسع في الدراسات والأبحاث للكثف عن مصادر المياه المختلفة واستثمارها (يوسف وآخرون،

في القطر العراقي هنالك عدد من الأنهر والخزانات المائية يقع معظمها في النصف الثمالي منه، تختلف هذه الأنهار والخزانات المائية في أعمارها وسعتها وملوحة مياهها في نوعية وكمية الأحياء التي تقطنها ولكنها تشترك جميعها في دورها المهر

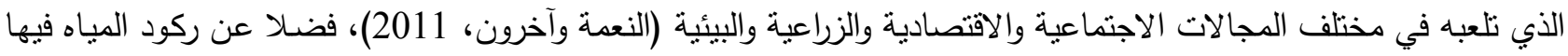
مما يؤدي إلى تردي نوعية المياه مع مرور الزمن وبما أن الأنهر ليست فنوات تمر فيها المياه فقط بل هي وحدة بيئية متكاملة أو ولئه

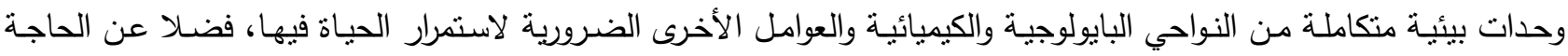
الملحة والضغط الموجود على استعمالات المياه بصورة مستمرة سنة بعد سنة تزيد من التأثير على هذه الوحدات البيئية وقد يتخلخل لئل لئل توازنها أو بقائها وهذا يجعل مراقبة وصيانة هذه الأنهار والمياه فيها بصورة عامة ضرورية وخاصة من قبل المختصين في البيئة.

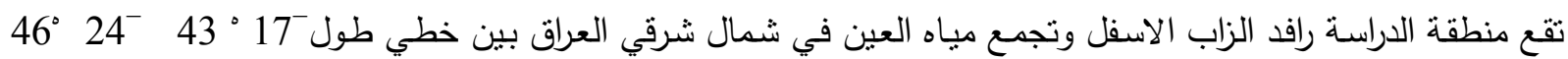
وبين دائرتي عرض كنئ حيث يصل طول هذا النهر حوالي 400 كم والاسم الثائع له هو الزاب الصغير وهو أطول من الزاب الأعلى والكبير بحوالي 8 كم

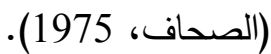

جيولوجيا، منطقة الدراسة تكونت من ترسبات العصر الطباشيري وتتكون من صخور كلسيه عادة وجيرية وصخور نارية ومتحولة ورسوبية (عبد الجبار ، 1981).

إن الدراسات البيئية على الأنهر في العراق قد اقتصرت على نهر دجلة والفرات وشط العرب، مثلا دراسة الصحاف (1975) على نهر دجلة والفرات والتي بينت فيها إن الملوحة في نهر دجلة والفرات تزداد بعد دخولها العراق وان الملوحة في نهر

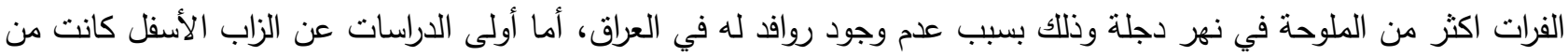
قبل (Shaban,1980) والتي تضمنت دراسة بحيرة دوكان وموقع واحد على نهر الزاب الاسفل والتي توصل فيها إلى زيادة أعداد الهائمات والذي يؤثر في قيم الكلوروفيل إذ تجاوزت أعدادها 650000 خلية في اللتر الواحد، ولاحظ (1981) في دراسته على الزاب الأسفل زيادة العكورة وقابلية التوصيل الكهربائي وان تراكيز الفوسفات والنترات والنتريت والسليكا لم تتجاوز الحد المسموح بها. تهدف الدراسة الحالية الى معرفة الاختلافات في بعض الصفات الفيزيائية والكيميائية والاحيائية لنظامين بيئيين هما نهر الزاب وتجمع مياه العين القريية منه. 
المواد وطرائق العمل

1 - - عينات المياه (الفحوصات الفيزيائية والكيميائية):

تم جمع عينات المياه من نهر الزاب الأسفل ومجمع لمياه العيون بالقرب من قرية شميط والتابعة إداريا الى ناحية الزاب -

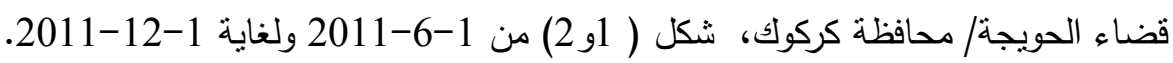

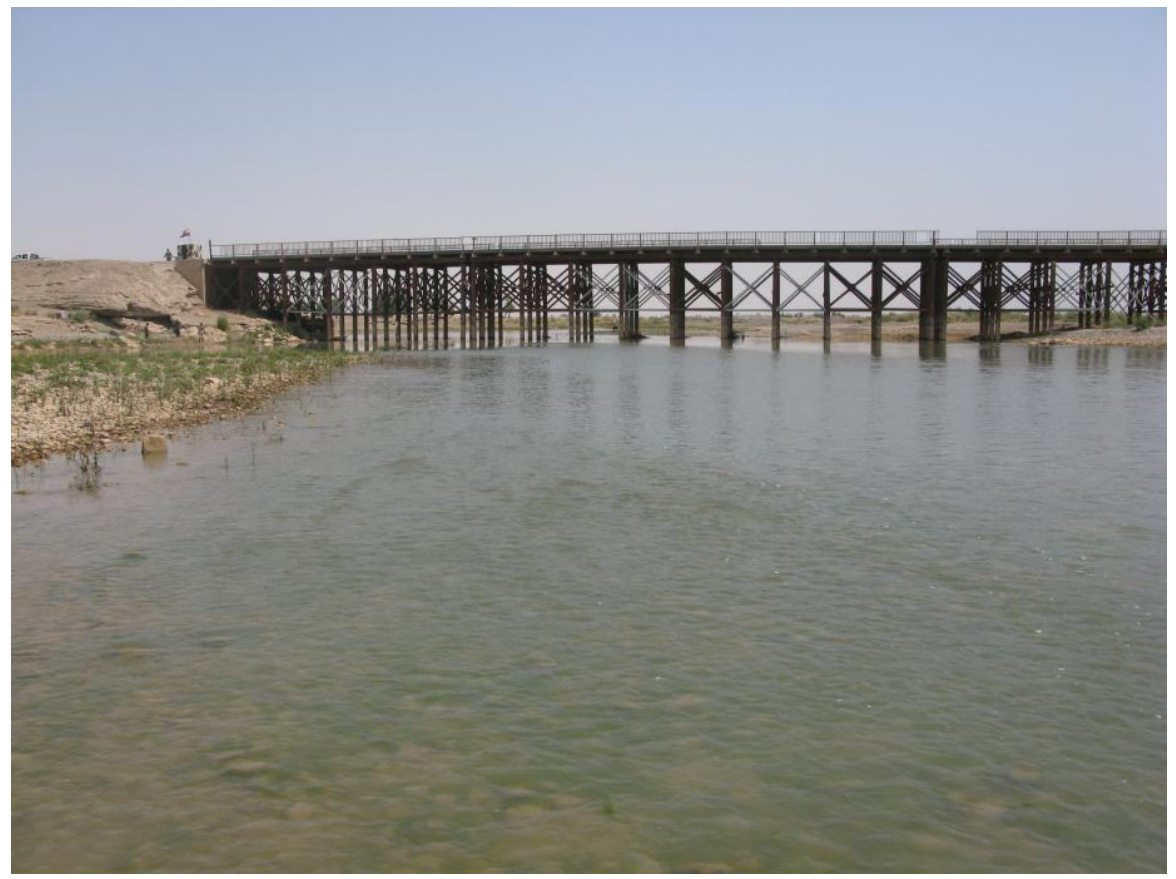

الشكل 1: نهر الزاب بالقرب من قرية شميط في قضاء الحويجة/ كركوك

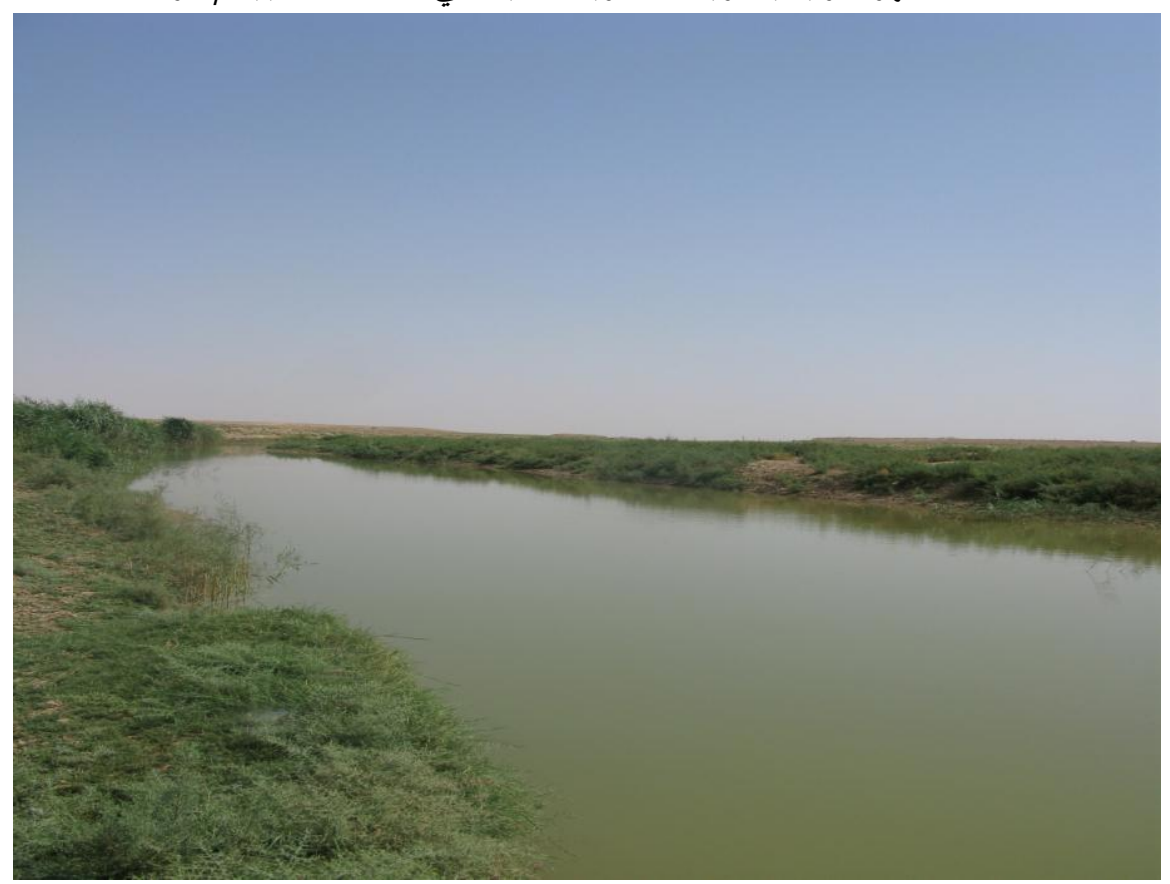

الشكل 2: مجمع مياه عين وادي الفضا 
أجريت على العينات عدد من الفحوصات الفيزيائية والكيميائية وفقا ماجاء في (APHA,1975) حيث قيست التوصيلة الكهربائية باستخدام جهاز EC meter، وسجلت القراءة بعد تعديل درجة حرارة الجهاز بحيث تكون مساوية لدرجة حرارة العينة،

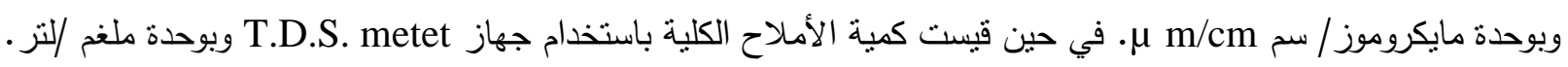
أما درجة حرارة الهواء والماء تم استخدام محرار زئبقي ذات تدرج 50 درجة، الأيونات الموجبة Cations الكالسيوم والمغنيسيوم قيست بطريقة التسحيح ضد محلول Na2EDTA القياسي (0.02 N) وتم التعبير عنها بوحدة أيونا الصوديوم Na والبوتاسيوم Kaيس تركيزهما باستخدام جهاز مطياف الفوتومتري باللاهب.

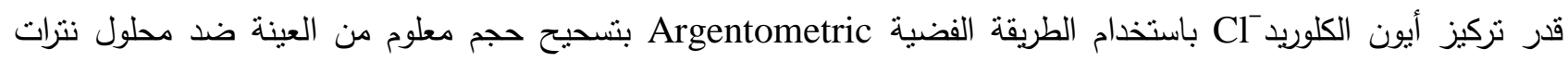
الفضة القياسي 0.014N

2- 2 - الفحوصات الإحيائية (العد الكلي للبكتيريا): تم قياس العدد الكلي للبكتيريا باستخدام وسط Nutrient agar وإنباع طريقة العد بالأطباق (Standard plate count) والتي حددت من قبل منظمة الصحة العالمية (عباوي وحسن، 1990).

\section{النتائج والمناقشة}

1- درجة حرارة الماء والهواء: يتبين من الجدول (1) أن معدل درجتي حرارة الهواء والماء بلغ (28 و 25) مرة م على التوالي هذا بالنسبة إلى مياه الزاب الأسفل، في حين بلغ معدل درجة حرارة الهواء والماء لتجمع مياه العين (26 و 23) م على التوالي. من المعلوم أن درجة حرارة المياه في المسطحات المائية تكون مرتبطة مع درجة حرارة الهواء والتي بدورها تكون مرتبطة بالموقع الجغرافي للمسطح المائي

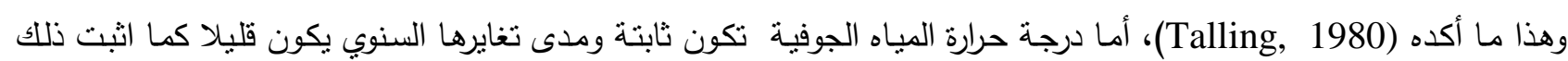
(كنه، 2001) في دراسته عن المياه الجوفية في محافظة نينوى.

2- قابلية التوصيل الكهريائي:

توضح النتائج في الثكلين (3 و4) أن أعلى قيمة لقابلية التوصيل الكهبائي كان خلال شهر حزيران في مياه الزاب الأسفل إذ بلغ (1020) مايكروموز /سم، في حين بلغ أوطأ قيمه لله خلال شهر اب (350) مايكروموز / سم، أما في تجمع مياه

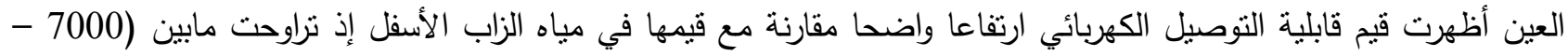
9995) مايكروموز/سم. تستعمل قيمة التوصيل الكهربائي للتعبير عن كمية الأملاح المذابة وتزداد قيم التوصيل الكهربائي بزيادة الأيونات (بليغ، 1974) وهذا ماأكده (كنه والجبوري، 2007) في دراستهما للابار الواقعة في منطقتي حمد اغا التضاني ومجمع حطين، وان قيمة التوصيلة الكهربائية قد تقل مع بداية سقوط الامطار كما في دراسة (عبدالجبار، 1981) على الزاب الاسفل، وان

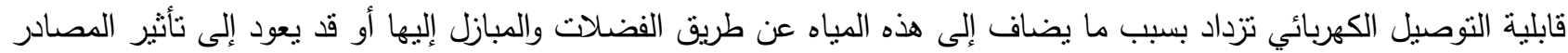
المختلفة لمياه الداخلة إلى الزاب في مجراه والتي تتمايز كثيرا في خواصها، إضافة إلى التركيب الجيولوجي لكلا منطقتي الدراسة. وحسب قيم قابلية التوصيل الكهربائي للاراسة الحالية ومدى ملائمة المياه لزراعة الدحاصيل فان تجمع مياه العين تستخدم

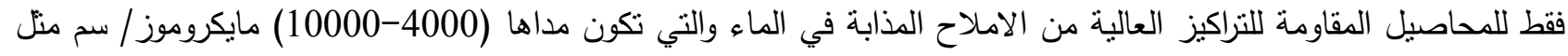
اشجار النخيل في حين ان ماء الزاب يستخدم للمحاصيل غير المقاومة للملوحة في الماء وتكون مداها (0.0-3000) مايكروموز/ مأهاء

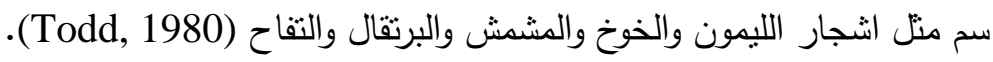



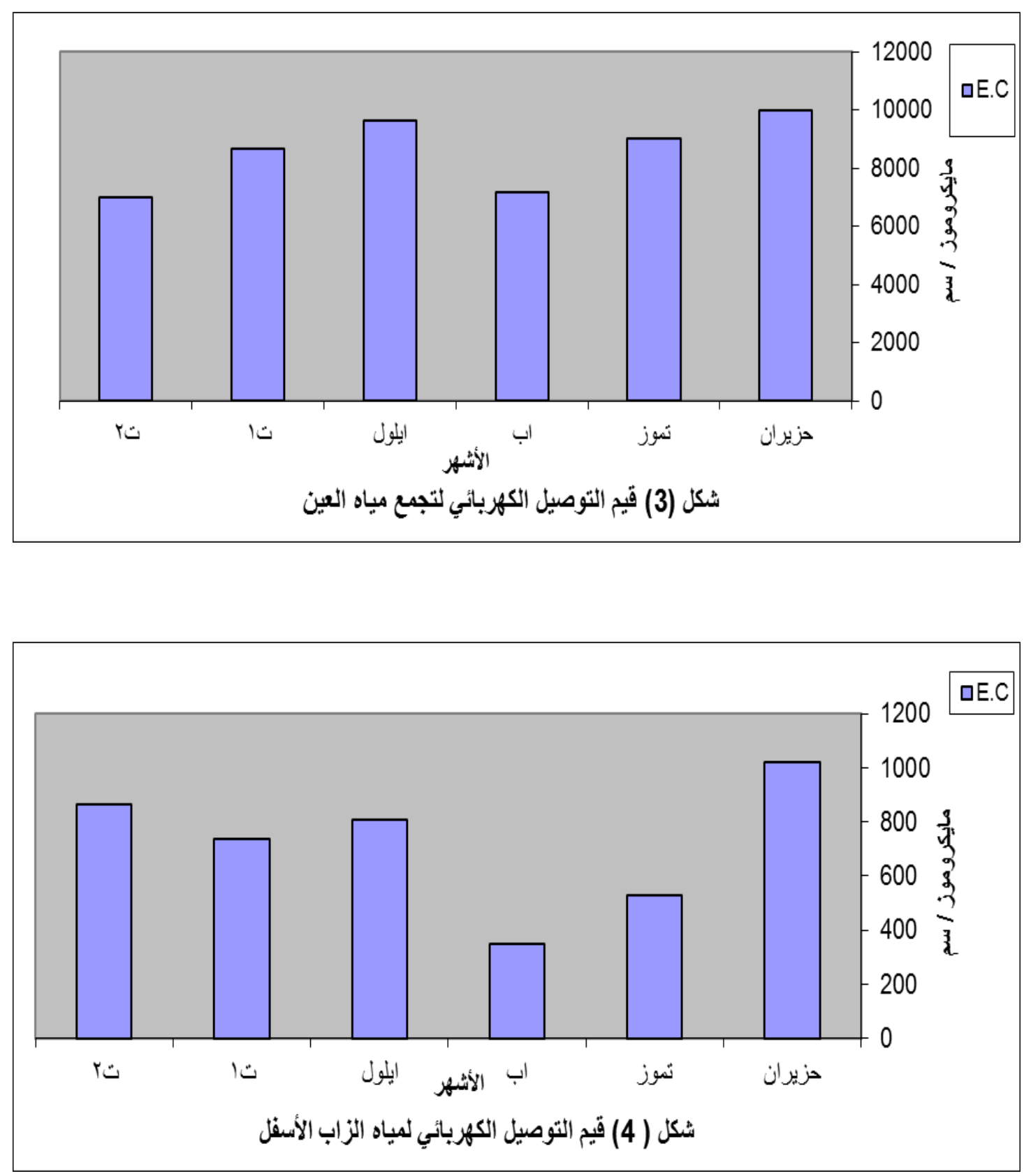

3 - 3مية الأملاح الكلية:

يبين (الجدول 1) أن تراكيز الأملاح الكلية حيث تراوحت بين (350 -815) ملغم /لتر في مباه الزاب الأسفل مقارنة مع تراكيزها في تجمع مياه العين إذ تراوحت بين (1499 -1648) ملغم / لتز • وبلغ معدل كمية الأملاح الكلية في مياه الزاب الأسفل

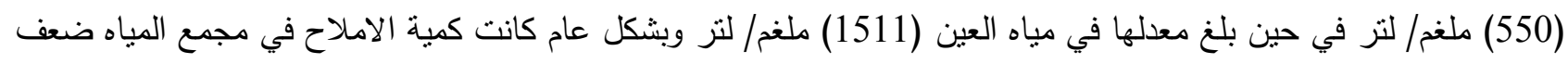
الى ثلاثة اضعاف كمياتها في الزاب الاسفل. إن الارتفاع في هذا العامل عادة يكون مرنبط مع قيم قابلية التوصيل الكهربائي ودرجة حرارة الهواء (علكم وآخرون، 2002؛ Al-Nakshabandi, 2002 فضلا عن التكوين الجيولوجي لمنطقة الدراسة الغني بالأملاح القابلة للذوبان في الماء. وعند مقارنة نتائج معدلات الأملاح الكلية (الجدول 1) للموقعين مع المحددات (الجدول 2) تبين بانها تقع خارج المدى المسموح به. 


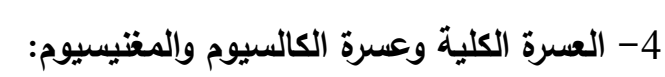
من الثكلين (5 و6) ينبين أن معدلات تراكيز العسرة الكلية وعسرة الكالسيوم والمغنيسيوم بلغت في مياه الزاب الأسفل 1456) (176، 125 ، 125 ) ملغم / لتز على التوالي مقارنة مع تراكيزها في تجمع مياه العين إذ بلغت معدلاتها

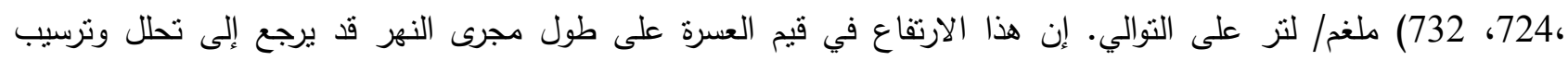

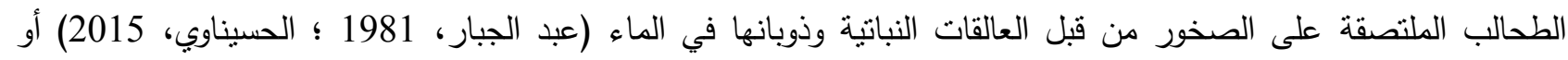
وصول جزء من تربة الضفاف الى النهر خلال مواسم الامطار والتي تحمل معها الأيونات الذائبة لأملاح العسرة، وتكون المياه السطحية اقل عسرة من المياه الجوفية بسبب النركيب الجيولوجي لمنطقة الدراسة الغني بالأملاح القابلة للذوبان (السعدي وآخرون، 1986). فضلا عن ان الانخفاض في قيم انواع العسرة يمكن ان يرتبط بسقوط الامطار التي تزيد من عكوره الماء (عبدالجبار 1981). (1986)

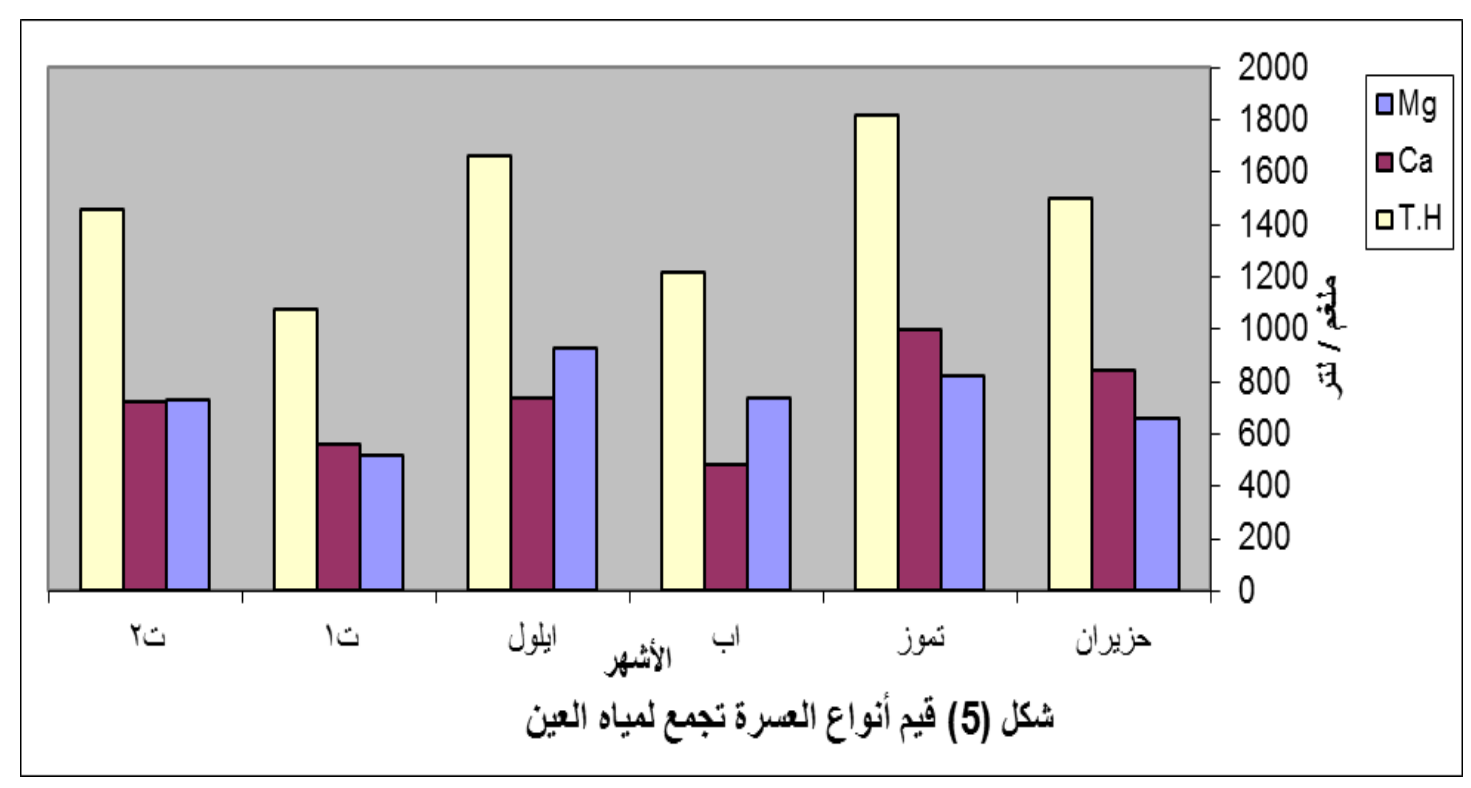




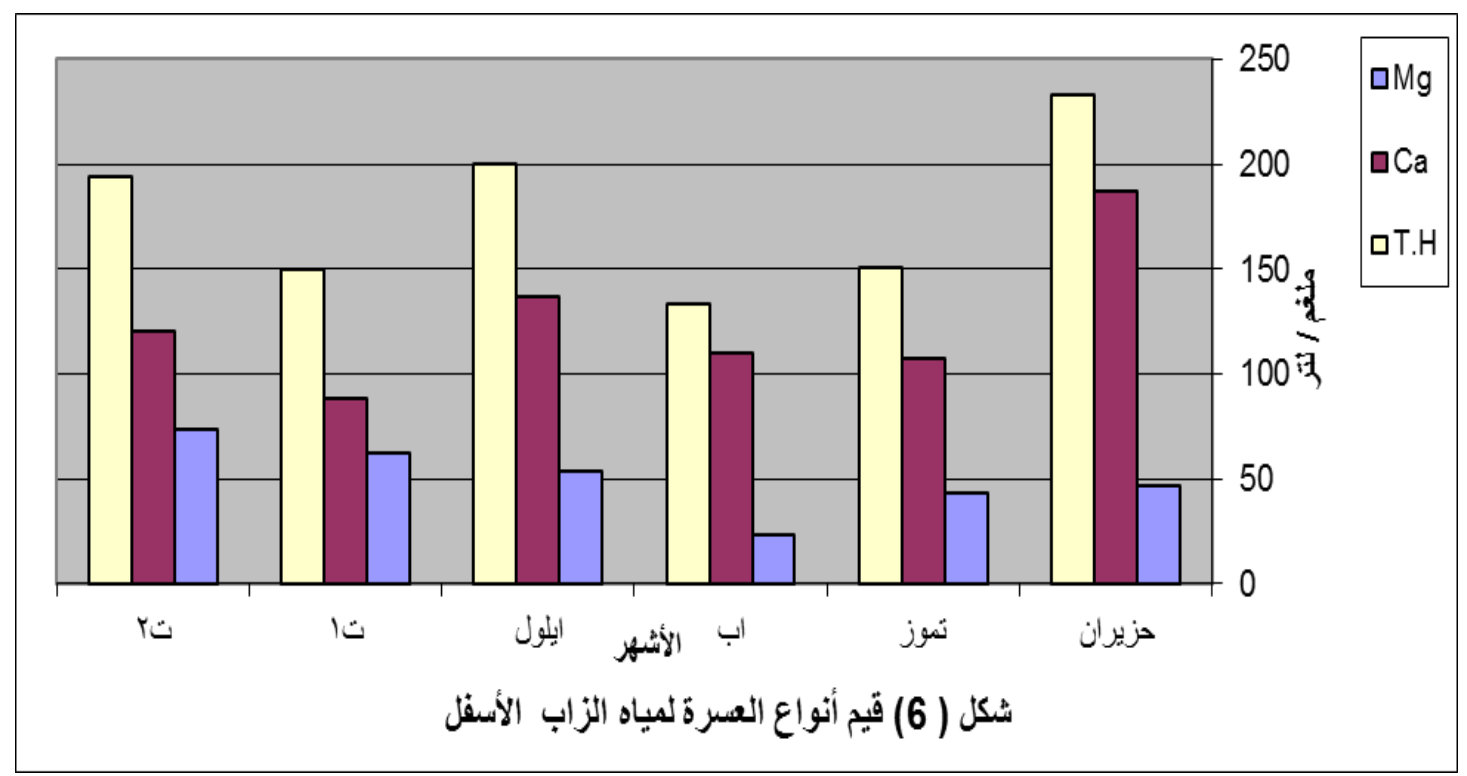

وعند مقارنة نتائج معدلات العسرة الكلية والكالسيوم والمغنيسيوم (الجدول 1) للموقعين مع المحددات (الجدول 2) تبين بأنها تقع خارج المدى المسموح به بالنسبة لتجمع مياه العين اما مياه الزاب الاسفل فهي ضمن المحددات المسموح به. 5- الكلوريدات: العدى العات

أظهرت النتائج المبينة في الثكلين (7 و 8) تغايرا واضحا في نركيزالكلوريدات في مياه الزاب الأسفل و تجمع مياه العين

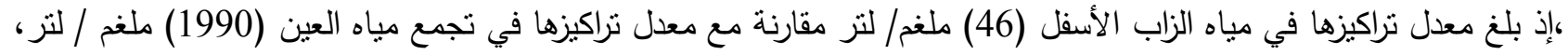
وان ايون الكلوريد هو الأكثز سيادة على بقية الايونات قيد الدراسة في المياه الجوفية وذللك لكون معظم أملاحه سريعة الذوبان بالماء هذا بالنسبة إلى تجمع مياه العين، إضافة إلى الفضلات الكثيرة والتي تطرح إلى النهر نتيجة النشاطات المختلفة أو قد يعود إلى التغيير والاختلاف المناخي (مني، 2001 ؛ العلاوي، 2017).

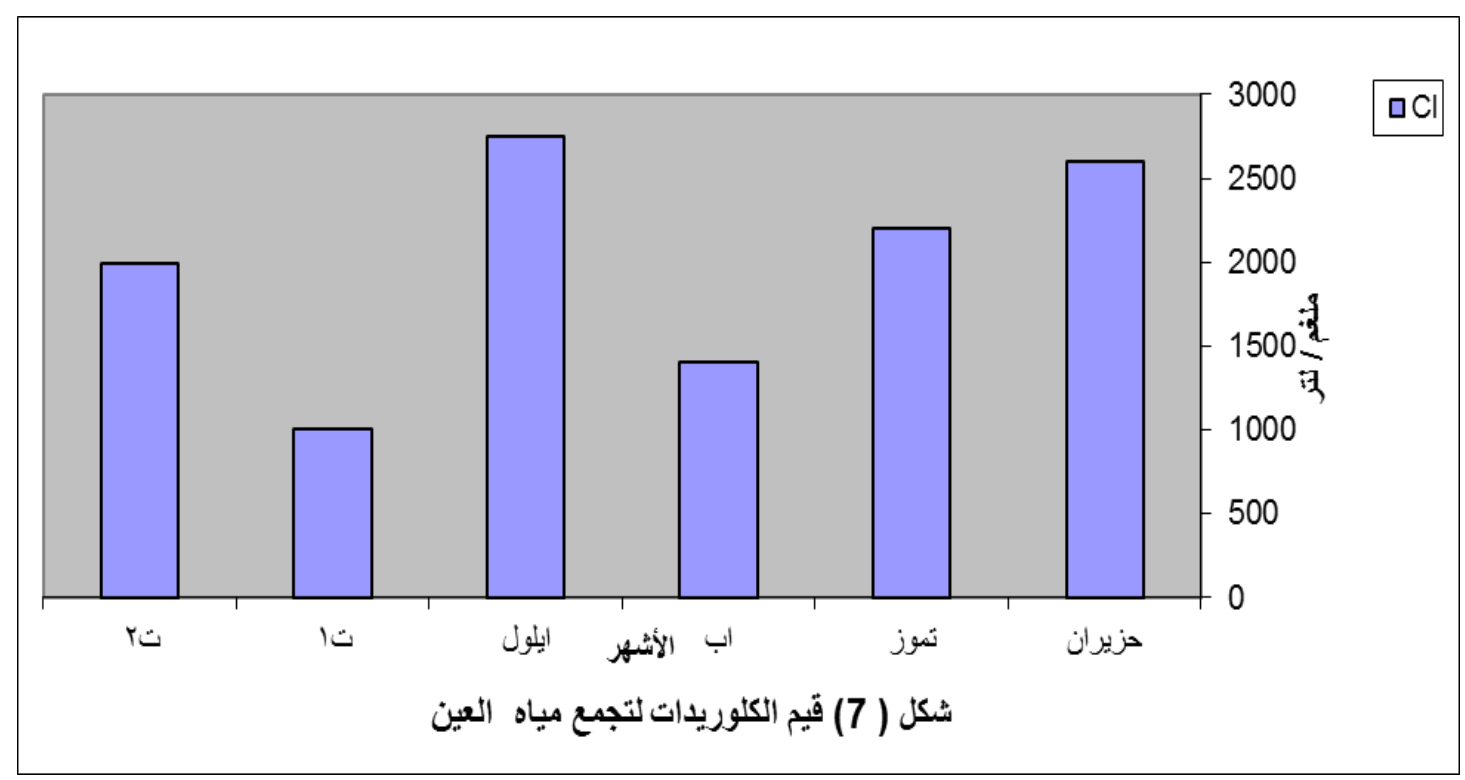




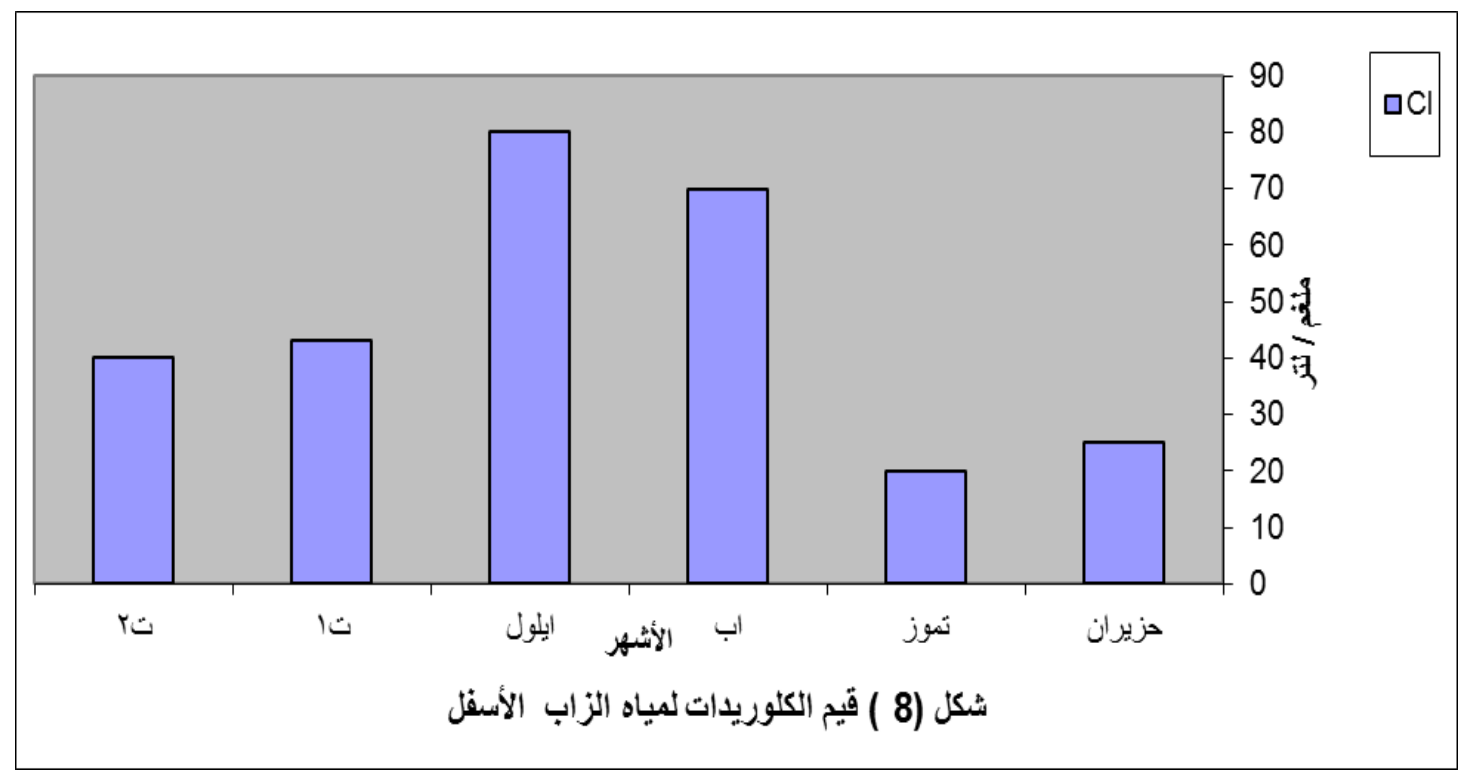

6 - 6 ايونا الصوديوم والبوتاسيوم:

أظهر تركيز هذين الأيونين اختلافا واضحا في مياه كلا الموقعين، فقد وصل عنصر الصوديوم الى أعلى ارتفاعا له خلا

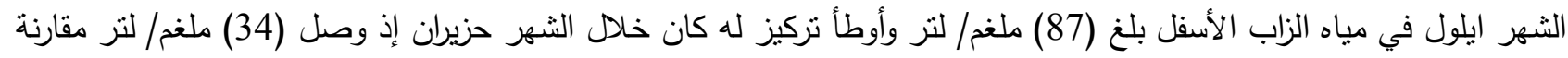

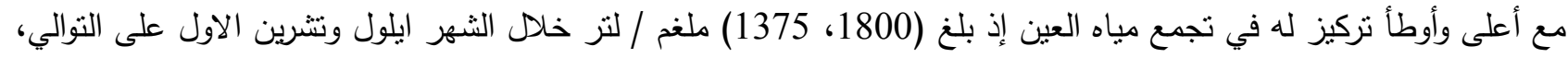
أما عنصر البوتاسيوم فقد أظهر تراكيز تراوحت ما بين (1,6 - 2,6) ملغم / لتر في مياه الزاب الأسفل مقارنة مع تراكيزها في لتربي تجمع مياه العين إذ تراوحت مابين (4 - 18) ملغم/ لتر • واوضحت نتائج الدراسة الحالية ان ايون البوتاسيوم يوجد بتراكيز قليلة

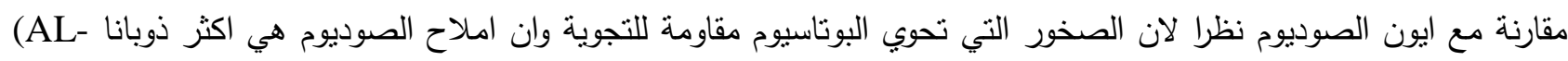
.Layla et al., 1990) إن الزيادة في نركيز هذين الأيونين في ماء الزاب قد يرجع إلى ناثير المياه المنسربة من المناطق المجاورة والجداول إلى الزاب

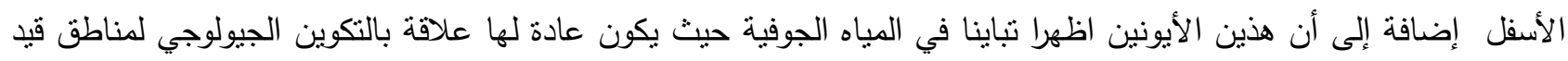
الدراسة. نلاحظ من الثكلين (9 و 10) إن نرتيب الأيونات الموجبة في مياه الزاب الأسفل كان لأيونات الكالسيوم في حين كانت السيادة في تجمع مياه العين لأيونات الصوديوم. 


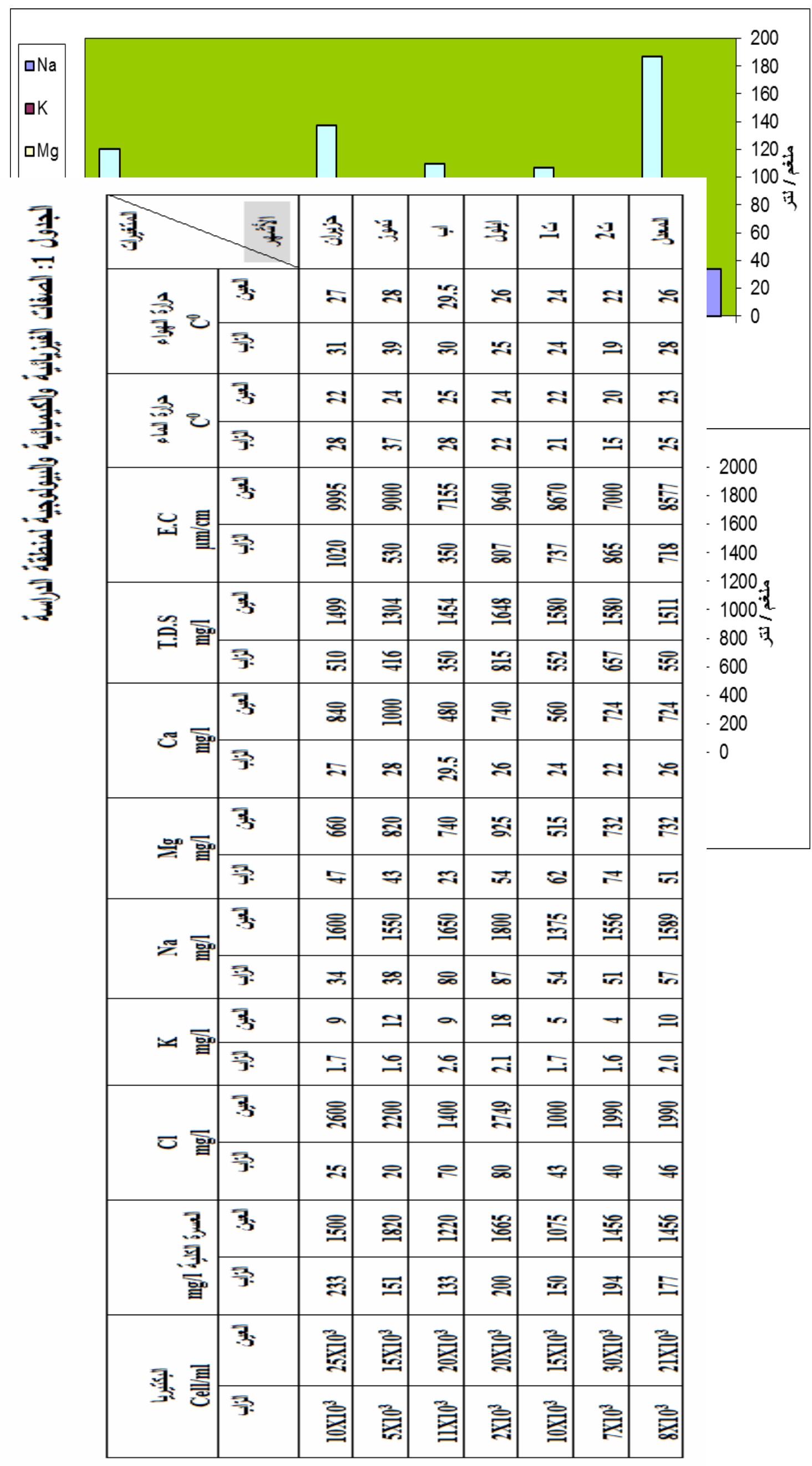


7 - العدد الكلي للبكتيريا:

نلاحظ من (الجدول 1) بان مياه نهر الزاب الأسفل و تجمع مياه العين كانتا ذات محتوى بكتثبري، إذ أظهر أعلى عدد

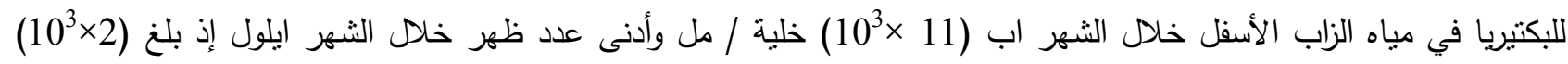

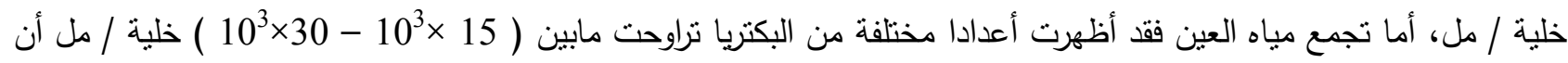

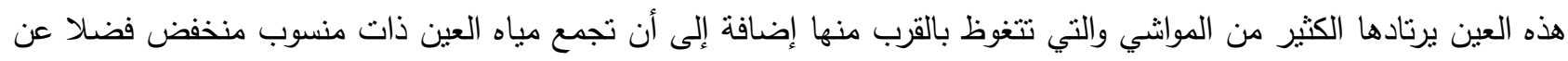
انه نظام بيئي راكد وركود الماء يفسده مقارنة بمنسوب مياه النهر الجاري الذي يحصل فيه تتقية ذاتية وعادة يحصل للبكتيريا عملية التخفيف (الباحث)، حيث أن المصادر المائية المختلفة عرضة للتلوث بالمسببات المرضية الناتجة من تصريف الفضلات البشرية أو الحيوانية إليها ومنها البكتيريا والفيروسات والأحياء المجهرية وحيدة الخلية إذ يعاني تلني سكان العالم من عدم توفر مياه آمنة ونقية وخالية من المسببات المرضية إضافة إلى ممارسة كثير من الأثخاص هواية السباحة في هذه المصادر المائية (العمر، . $(2010$

اعتمادا فقط على العدد الكلي للبكتيريا فقد تجاوزت المواصفات العالمية القياسية والموضوعة من قبل منظمة الصحة

العالمية (الجدول 2).

الجدول 2: المحددات القياسية لمياه الثرب حسب المواصفات القياسية العالمية لمياه الثرب (1971) والعراقية (1986) نقلا عن عباوي وحسن (1990).

\begin{tabular}{|c|c|c|}
\hline WHO & المواصفات العراقية & المحددات ملفم /لتز \\
\hline 500 & 1500 & TDS \\
\hline-- & 200 & $\mathrm{Ca}$ \\
\hline-- & - & $\mathrm{Na}$ \\
\hline-- & 150 & $\mathrm{Mg}$ \\
\hline 500 & 500 & العسرة الكلية \\
\hline 50 & 50 & Cell / ml العدد الكلي للبكتريا \\
\hline
\end{tabular}

\section{المصادر العربية}

بليغ، عبد المنعم (1974). استصلاح وتحسين الأراضي. دار المطبوعات الجديدة بالإسكندرية. الحسيناوي، صفاء حسين عبداله (2015). المحتوى البايوكيميائي لبعض الطحالب الدقيقة وتاثير بعض العوامل البئية والملوثات

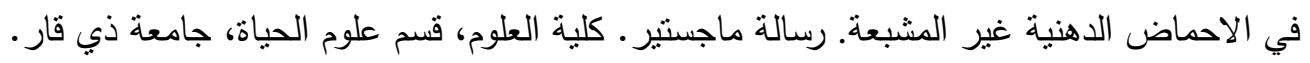

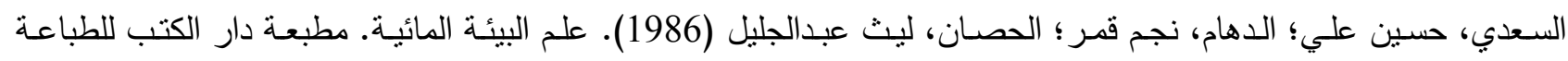

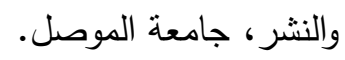

الصحاف، مهدي (1975). الموارد المائية في العراق وصيانتها من التلوث. منشورات وزارة الأعلام، العراق. علكم، فؤاد؛ حسن، فكرت مجيد؛ السعدي، حسن علي (2002). التغيرات الفصلية للخواص الفيزيائية والكيميائية لبحيرة سـاوة، العراق. ابحاث البيئة والنتمية المستدامة.

عبدالجبار، رياض عباس (1981). دراسة بيئية على الزاب الأسفل. رسالة ماجستبر . كلية العلوم/ جامعة السليمانية.

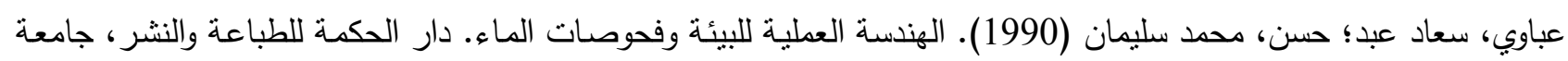
الموصل. 
العلاوي، احمد ابراهيم عبداله (2017). معالجة مياه فضلات الصرف الصحي باستخدام انواع من الطحالب. رسالة ماجستير،

$$
\text { كلية العلوم، قسم علوم الحياة. جامعة تكريت. }
$$

العمر، مثثى عبد الرزاق (2010). " التلوث البيئي". الطبعة الثانية، دار وائل للطباعة والنشر، عمانة فان/الأردن.

كَنَّه، عبد المنعم محمد علي (2001). دراسة نوعية المياه الجوفية الكبريتية في محافظة نينوى. رسالة ماجستير ، قسم علوم الحياة/ كلية العلوم/ جامعة الموصل.

كََّه، عبدالمنعم محمد علي؛ الجبوري، محمود إسماعيل (2007). أثر التكوين الجيولوجي على المياه الجوفية المستخدمة للأغراض

المختلفة في منطقتي حمد أغا التضاني ومجمع حطين (شمال غرب العراق). مجلة التربية والعلم، 2(1).

مني، عامر احمد غازي (2001). موسوعة علمية في سبل حماية بيئة المصانع. مطبعة دار الحرف العربي بغداد/ العراق.

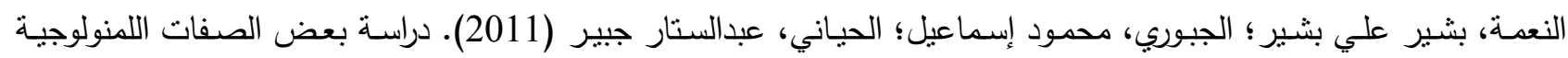

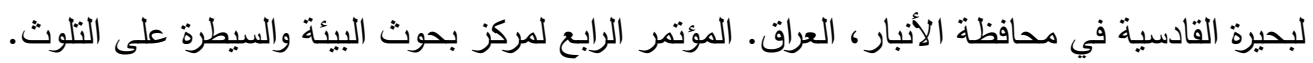

يوسف، محمد سليم؛ اليازجي، ياسر ميسر ؛ العباسي، محمد وليد (2008). الخصائص النوعية لمياه عين صوباشي في مدينة تلعفر/شمال غربي العراق. المؤتمر العلمي الدوري السادس لمركز بحوث السدود والموارد المائية .

\section{المصادر الأجنبية}

Al-Layla, A.M.; Al-rawi, S.M.; Al-awaz, H.A. (1990). Saddam lake used drinking and domestic. $2^{\text {nd }}$ sci. Conf. Saddam dam research center. Mosul Iraq.

Al-Nakshabandi, I.Y. (2002). A phycolimnological study on Duhok impoundment and its main watershed. PhD Thesis, Agriculture Univ. of Duhok.

APHA, (1975). AWW A and WPCF. "Standard Methods for the Examination of Water and Wastewater". $14^{\text {th }}$ ed., A.P.H.A., USA, 1193 p.

Shaban, A.A. (1980). An ecological studies on phytoplankton in Dukan lake. M.Sc. Thesis Univ. Sulaimaniyah. Iraq.

Talling, J.F. (1980). Water characteristics in Euphrates and Tigris Mesopotamian ecology and destiny by Julian Rzoska. Mono Graphiqne Biologicae. 38.

Todd, D.K. (1980). "Groundwater hydrology". John Wily and Sons. Inc., Toppan printing company. New York and London.

WHO. ( 1971). "International standards for drinking water". $3^{\text {rd }}$ ed. New York. 